\title{
Art Education Development in the Context of Global Changes
}

\author{
Iryna $\mathrm{V}$. Yefimenko
}

Vinnytsia Mykhailo Kotsiubynskyi State Pedagogical University, Vinnytsia, Ukraine

\section{Olena M. Yakymchuk}

Vinnytsia Mykhailo Kotsiubynskyi State Pedagogical University, Vinnytsia, Ukraine

\section{Nataliia Ye. Kravtsova}

Vinnytsia Mykhailo Kotsiubynskyi State Pedagogical University, Vinnytsia, Ukraine

\section{Halyna I. Sotska}

Ivan Ziazun Institute for Teacher Education and Adult Education of the National Academy of Pedagogical Sciences of Ukraine, Kyiv, Ukraine

\section{Anatolii M. Korol}

Pavlo Tychyna Uman State Pedagogical University, Uman, Ukraine

\begin{abstract}
New trends are emerging in the system of higher art education due to globalisation and integration, rapid development of technological innovations. The use of technological innovations causes emerging of new types of communication, collaboration and interaction between teachers and students. In the article, the concept of smart education and its principles and the competence of a future teacher and specifics of their professional training were described. Global educational trends were characterised. The perspectives of professional and pedagogical activity of art teacher were outlined. The importance of technological innovations in the process of innovative education was explained. The criteria for assessing the teacher's innovative competence were highlighted. It was established that the modern smart society requires a teacher who teaches art history while constantly developing his cognitive abilities, systematically renew his intellectual and creative potential. The peculiarities of teacher's innovative competence formation in the changing conditions of a modern "smart" society were investigated. It was concluded that digital competence is one of the new requirements for art critics
\end{abstract}

Linguistics and Culture Review (c) 2021.

Corresponding author: Yefimenko, I. V.; Email: i-yefimenko@uohk.com.cn

Manuscript submitted: 9 April 202 1, Manuscript revised: 27 June 2021, Accepted for publication: 23 July 2021 
training in the context of the development of the information-oriented society.

Keywords---education, modern society, modern teacher, social development, technological innovations.

\section{Introduction}

At the modern stage of social development, which is characterised by globalisation and integration, an increase in the availability of information resources, means of communication, and the rapid development of technological innovations, a broad foundation is being created for the development of modern updated education paradigm. This ensures the shaping of a highly professional, competent art critic of a new generation, capable of comprehending traditional works and the latest achievements of artistic science. Such specialist will be able to generate new ideas, work creatively in a team, use innovative approaches during educational activities in the renewed school (Schoner et al., 2007).

In accordance with the requirements of the modern information-oriented society, new trends are emerging in the system of higher art education - general trends characteristic of the educational space development (Tiejun, 2017; Desai et al., 2009). Smart education is one of the main educational trends in modern higher education, since it most accurately reflects the current priorities for education development (Milman \& Heinecke, 2000). In the English language, the lexical item "smart" corresponds to many different translation options, which are based on such meanings as smart, technological, efficient (Zhu \& Berry, 2018). The term was coined in the context of aerospace technologies, which were marked by the transition to new materials and their innovative possibilities, as well as advances in the field of electronics and information technology (Starchikova et al., 2018). In the practice of educational activities, the overwhelming majority of teachers identify the concept under consideration with the usage of technological innovations and interactive teaching methods that contribute to the development of professional competencies in future specialists based on a systemic multidimensional vision and study of disciplines, taking into account their multidimensionality and continuous content updating (Burnard, 2017).

The intensive introduction of modern technologies, services and Internet resources has led to a new stage in the development of the information space, which today is designated by the term "smart society". It received special publicity after the Seoul G20 Summit, during which strategic directions for the development of smart technologies in the world's major economies (Germany, South Korea, the Netherlands, etc.) were announced (Kravtsova, 2017). Smart society is characterised by rapid changes in the external environment, adaptation to new conditions, and independent development. In accordance with this, the tasks of higher education are also changing, which consists in preparing specialists with creative potential, capable of living in modern conditions of the information society, able to work in a new way, changing the nature of interaction (Bedi et al., 2011). The goal of smart learning is to provide future art experts with 
the skills necessary to carry out effective professional activities in a digital society and rapid economic development (Robertson, 2012; Seligmann, 2014).

The implementation of modern education is ensured by the use of technological innovations and the Internet, which contribute to the search for new types of communication, collaboration and interaction between teachers and students (Delatte et al., 2013). Thanks to the unification of higher education institutions, the provision of free access to content, the joint activities of teachers to organise flexible, interactive learning, innovative education was created (Psacharopoulos, 1994; Vesper \& Gartner, 1997).

\section{Specifics of concepts and principles of smart education}

The concept of modern education is the development of an intellectual teaching environment, ensuring the continuous development of the competencies of participants in the educational process by means of technological innovation (Calderhead, 1989; Realini \& Marcos, 2014). The concept of smart education implies mobility of learning, flexibility in the use of didactic material, a variety of multimedia tools, the independence in searching and digestion of information, introducing technological innovations into pedagogical practice, generating new ideas, knowledge, and developing creative skills. So, in the concept of modern education in South Korea, seven basic skills of a modern specialist are defined:

- Critical thinking and problem solving.

- Creativity and innovation.

- Cooperation and leadership.

- Intercultural understanding.

- Communication.

- Literacy in the field of information and communication technologies.

- Career and life skills.

In the framework of the study, the global educational trends highlighted in the Forbs magazine are especially valuable and correlated with the provisions of the Concept of modern education:

- Prevalence of distance learning technologies.

- Personalisation and unification of education in order to increase motivation.

- Gamification" of education (using game situations in the learning process).

- Introduction of interactive textbooks that ensure the multidimensionality of the modern educational environment.

- Interactive immersion" in the virtual world.

In line with the problem under consideration, we note that the process of informatisation of education presupposes a radical restructuring of the entire education system (Bereczkei \& Csanaky, 1996; Jovanova, 2010). Changing the structure of the educational process, forming other methodological and didactic foundations, providing a competency-based approach, which requires from art teacher not only a system of knowledge of scientific theories, ideas and concepts of art, but also key competencies. Smart education has become a "new philosophy 
of education", which involves generation of new ideas and knowledge, development of critical thinking, creativity, digital literacy, intercultural competence, ability to collaborate and compete in the modern digital space.

In theoretical and scientific thought, the basic principles of smart education are formulated (Sacchetti \& Belardo, 2015). First, the use of information in the educational program that meets the most important needs of our time, in order to solve educational problems. The modern globalised society is characterised by the rapid growth of information flow. That is why the existing teaching materials require systematic updating in order to prepare students for solving practical problems in future professional activities (Stevens et al., 2010). Secondly, the organisation of independent research, project activities of students. Scientists place an emphasis on the crucial importance of this very principle in the process of preparing specialists for creative professional activity, independent and research work. Thirdly, the learning process should be continuous and provide for training in a professional environment, using the means of professional activity. Fourth, the organisation of professional interaction with specialists. During the educational process, students should interact with professionals in order to gain positive experience. Fifth, providing ample opportunities for the flexibility of individualised training and study of educational programs and courses (Isabelle, 2017).

Taking into account the above principles, we can note that smart education constitutes a new educational paradigm that ensures the development of competencies of future art experts for flexible, creative interaction in modern society and thus serves as an important tool for shaping the readiness of specialists in the art industry to innovate (Elena, 2014; Bezukladnikov \& Kruze, 2015).

\section{Features of the development of innovative competence of a teacher of art specialties}

The transition to a new paradigm of smart learning predetermines new requirements for an art teacher who is aware of his role in a digital society, constantly improving himself, his own personal and professional qualities, uses flexible, non-standard approaches to learning, and is also capable of adapting to fast-paced living conditions. The organisation of innovative education provides for the creation of educational activities for the independent acquisition of knowledge, skills and abilities by young people (Ulug et al., 2011; Huebner, 2005). The function of the teacher in the context of smart education is high-quality content navigation, rather than the broadcast of ready-made truths and the transfer of knowledge.

In the process of scientific research, it was found that the new philosophy of education entails the expansion and renewal of the teacher's functions. Meeting the requirements of the updated school, the activities of an art teacher should be of a consultative nature. A modern teacher is a mentor who coordinates the cognitive process of students, ensures the improvement of educational material, constantly takes care of increasing creative activity and professional and pedagogical qualifications. The platform of smart education provides art teachers with new opportunities to improve their professional and pedagogical competence. 
Thanks to the wide access to the knowledge from all over the world, teachers have the opportunity to freely exchange experiences and ideas, pay more attention to self-education, personalise the course of study in accordance with its purpose and the individual characteristics of students, save time. Determining the global strategies for the smart society development, one more feature of the activity of a modern teacher is identified, which is introduced on the Internet through the presentation of his own experience: portfolio; web pages; counselling; video lessons, web conferences; master classes; distance learning; web projects, virtualisation of scientific research (Jasonides et al., 2016).

In the conditions of smart learning, new perspectives of professional and pedagogical activity open up for a teacher of art: ensuring prompt communication with students; use of information and communication training tools; various types of multimedia; application of technological innovations; creation of a network for the exchange of information between other educational institutions and the establishment of cooperation with colleagues, including foreign ones; an increase in the volume of independent and group work; combining real and virtual space. In the course of the study, it was found that the expansion and renewal of the activities of art history teacher in the conditions of modern education, respectively, sets new tasks for mastering innovative teaching technologies (Kryvylova et al., 2021; Pakhomova et al., 2021).

The focus of education on a competence-based approach, in our opinion, helps to maintain the correspondence of educational conditions to the needs of modern society, caused by dynamic economic development and information explosion. The competence-based approach is based on the essence of the concept of "competence", which is also often equated with competency. Competency is defined as a certain rule, the norm of the student's educational training. Competence is the high level of competency, which presupposes highly developed personal qualities of the student and work experience. Competency is referred to as a structure, characterising a competent teacher as a specialist who has inherent in-depth knowledge of a specific subject of a university education. The competence of a future teacher must be formed during professional training in the field of knowledge of that science, which is the main subject of his future professional activity.

In the process of scientific inquiry, it was found that now of significant interest of scientists are issues of the formation of professional competence of a specialist as an important condition for the smart society functioning. Modern research has proven that the world's leading countries (USA, England, Germany, France) are characterised by the shift in emphasis on the requirements of a modern worker: the social values of his personal qualities come to the fore. American sociologists have developed a model of a "competent worker", in which an attempt is made to highlight a wide range of individual psychological qualities of a specialist, which, in our opinion, correspond appropriately to the requirements of modern society: discipline, independence, communication, striving for self-development. In the context of the subject matter, such quality as the ability to self-improvement, which presupposes a process of independent learning, in which a person perceives the rules, transforms them at the subconscious level, taking into account developed abilities and needs, is of particular importance. 
Based on today's realities and the requirements of modern society, the leading task of the professional and pedagogical training of specialists in foreign language education is the formation and development of personality, capable of subjectsubject interaction in the process of organising a foreign learning space, creating an intellectual creative atmosphere, using innovative educational technologies. In accordance with this, the importance of the innovative component of the professional and pedagogical competence of the future teacher is significantly enhanced, which allows us to emphasise the role of the innovative competence of a specialist in the art industry in the conditions of modern education. Emphasising the importance of the innovative competence of a future specialist, it should be noted that its absence delays the professional development of a highly qualified specialist (Cassiday, 2011).

Based on the works of scientists on pedagogical innovation Bedi et al. (2011); Burnard (2017), it was found that the innovative competence of a teacher is one of the subsystems of his general professional and pedagogical competence. In the context of the organisation of smart learning, the formation of the teacher's innovative competence ensures compliance with the general and specific requirements for the teacher's activities at all stages of the implementation of smart learning. The structure of the teacher's innovative competence is represented by external (goal, means, object, subject, result) and internal (motivation, content, operations) components that ensure the implementation of pedagogical activities based on the principles, standards and technologies of modern education. The content of knowledge, skills, and abilities that ensure the effective use of technological innovations contributes to the effective implementation of the functions of innovative activities (gnostic, predictive, design, constructive, communicative, organisational) in accordance with modern trends of the information-oriented society development. There are the following criteria for assessing the teacher's innovative competence (Vitytė, 2016):

- Individual readiness for the demonstration of professional and pedagogical skills when solving standard and non-standard tasks.

- Motivational values-based attitude towards technological innovations.

- Adjustment level to new conditions for society development and modern requirements for specialists in the respective industry.

- Availability of a system of theoretical knowledge and a set of practical skills.

- Experience in applying knowledge in real situations of the pedagogical process.

- Ability to creatively solve problem situations, possession of modern innovative teaching technologies.

- Self-awareness and self-assessment of personal knowledge level, abilities, skills, opportunities necessary for the effective implementation of innovative activities.

- The ability to self-reflection and self-correction of their own innovative activities.

The innovative competence of a teacher of art specialties determines the use of updated, more effective forms, methods, means of teaching art history and, accordingly, allows to achieve qualitatively new results of mastering art history, obtained as a result of the implementation of technological innovations. In the 
process of scientific research, it was revealed that in the models of structures of innovative competence, there is a systemic combination of its social, personal and professional-technological spheres, which determine the high professionalism and pedagogical skill of the teacher. The level of development of the personality sphere directly affects the quality of the operational components of innovation, since the teacher's positive attitude to technological innovations, awareness of their importance ensures the effective use of innovations in the educational process, which determines the generation of new ideas and knowledge, the development of an innovative environment and modern society.

\section{Characteristics of the components of the teacher's innovative competence}

Integrating the findings of previous study by scientists Milman \& Heinecke (2000); Schoner et al. (2007), we define the innovative competence of a specialist as an integrative personality trait, which is the result of a combination of foreign language training, practical professional pedagogical and personal experience, which determines a high level of mastery of technological innovations and is a necessary requirement of modern education. Based on the analysis of scientific and pedagogical sources Tiejun (2017); Vitytè (2016), we consider it expedient to single out the following components of the innovative competence of teachers: social competency, motivational value competency, cognitive competency, technological competency, digital competency, reflexive regulatory competency.

Social competency is interpreted in pedagogical circles as the unity of social knowledge, skills, qualities and social experience of an individual. The presence of a social component in the general structure of the teacher's innovative competence ensures his ability for intellectual interaction in a social environment and his willingness to take responsibility for the results of the presented professional and pedagogical activities. We adhere to the opinion that social competence depends on the environment, the life of society, the social activity of the individual. It provides the ability to interact, the ability to overcome obstacles in everyday life, the skills to establish contacts, the ability to highlight important social and civic values, discursive skills, mobility and flexibility in various conditions of socialisation, ability to determine personal role in society. In modern society, the process of socialisation of the teacher's personality, his personal and professional self-determination are closely related to the mastery of technological innovations that develop critical thinking, creativity, computer literacy, intercultural communication, the ability to act and cooperate in a smart society.

Considering the importance of technological innovations in the process of innovative education, the authors note that the development of innovative competence of future specialists is associated with the processes of socialisation and personal and professional self-determination by introducing innovative technologies for teaching art history in their own work experience. Thus, the concept of modelling competence is based on the concept of the composition, structure and functions of social experience (Çil et al., 2016). Consequently, the development of the innovative competence of the future teacher provides for the presence of a social experience, which makes it possible to interpret already known information in a new way, to interact productively in a modern 
information-oriented intercultural society, using technological innovations to improve own professional and personal status in society.

An expressive social and professional position is one of the main requirements that are put forward for representatives of the teaching profession, in particular in the conditions of modern education. It is because of social and professional activity development that the teacher manifests himself as a subject of innovative activity. On the one hand, the teacher's behaviour depends on the high requirements, conditions and opportunities that a smart society sets before him, and on the other hand, the teacher's behaviour is governed by internal factors needs, aspirations, values, motives and personal goals. The internal needs for achieving success, the subjective value attitude and the desire for professional self-realisation determine the presence of motivational and values-based competence in the implementation of the teacher's innovative activities.

As it is known, the problem of accounting for motives and incentives is considered as one of the leading in choosing an individual trajectory in the professional activity organisation, in particular innovative. So, the high professionalism of the teacher is conditioned, first of all, by the specific nature of the personality motivation, aspirations, values-based orientations and the like. The motivational sphere of innovative activity cannot be reduced only to the fulfilment of professional duties, this process also has a personal character, it requires taking into account those motives and incentives, life prospects of the teacher, which play the role of a system-forming factor in relation to other motives of innovative professional activity. In the structure of professional motivation, the following components are distinguished: vocational aptitude, intentions, needs for professional activity, motives, values, incentives, goals, expectations, individual meaning of professional activity, attitudes, readiness, interests (Desai et al., 2009). On the basis of this, polymotivated nature of innovation is noted, the stimulation and activation of which is provided simultaneously by several dynamic, interdependent factors. The dominant motive is referred to as the system-forming factor that ensures the unification of individual structural elements of the motivational sphere. At the same time, motivational activity is directional.

In the scientific and pedagogical literature, personal and pragmatist types of activity are distinguished. In the personal orientation of activity, the general structure of the motivational sphere is expressed, combining individual incentives and motives. The professional orientation is implemented in the system of a person's professional activity and is characterised by the presence of actual motives, integration links between individual motives, the degree of materialisation of individual incentives, the nature and strength of the influence of the dominant motive. In accordance with this, it is determined that the priority values, motives, needs characteristic of a smart society affect the direction of the future teacher's innovative activities. Personal orientations of motives, needs and incentives are revealed when the teacher formulates the goal of introducing technological innovations in the process of smart learning organisation. Consequently, the motivational and value sphere is an important component of the teacher's innovative competence, which is designed to stimulate the teacher to continuous self-improvement, professional and intellectual development with the 
aim of self-realisation and competitiveness in a resource-rich society, which requires a "smart", adaptive, flexible approach to the organisation of training.

Cognitive competence in the structure of a teacher's innovative competence is determined by the presence of a body of knowledge on technological innovations, which are used in solving problems in various conditions of professional and pedagogical interaction. The knowledge of the teacher of art specialties about the content and characteristics of innovative activities is the basis for the development and substantiation of innovative technologies for teaching art history in the context of modern education. To select existing effective technological innovations, update existing ones or design own technologies for teaching art history, a teacher must have a deep knowledge of innovative pedagogical technologies, the mechanism of their functioning, innovative approaches, concepts of teaching art, creativity, the ability to act and compete in the labour market in an innovative environment.

The modern smart society requires a teacher who teaches art history while constantly developing his cognitive abilities, systematically renew his intellectual and creative potential in modern society. The theory that the intellectual ability of a person is the leading one turned out to be valuable within the framework of the study. The following components of intelligence are distinguished (Seligmann, 2014):

- Synthetic ability (unconventional approach to a problem, going beyond the limits of knowledge).

- Analytical ability (identification of ideas for the purpose of their further development and implementation in practice).

- Practical skills (the ability to present own innovative ideas and prove their effectiveness).

Technological competence in the structure of a specialist's innovative competence is represented by a set of diagnostics, designing, constructive, communicative and organisational skills in the use of technological innovations in the process of teaching art. Diagnostic skills involve the collection and analysis of information on innovative technologies for teaching art history. Design skills enable the development and design of technological innovations in art history teaching. Constructive skills allow to consciously perform actions for the rational implementation of technological innovations in the process of teaching art history. Communication skills include the teacher's ability to present material creatively, emotionally, to lead pedagogical discourse in a foreign language, to effectively solve communication problems in the process of innovative pedagogical activity. Organisational activity is expressed in creating conditions for optimal subjectsubject interaction of participants using interactive learning technologies, Internet resources, and a variety of multimedia tools. The technological component in the structure of the teacher's innovative competence predetermines the consistency and optimality of his activities in the direction of introducing innovative technologies in the process of teaching art history.

As it is known, in recent years, the latest technologies have brought a lot of information, communication and technical capabilities to modern education. The 
allocation of digital competence as part of the teacher's innovative competence is predetermined by the need of modern society for the critical and responsible use and interaction of the teacher with digital technologies in order to create favourable conditions for the study and participation in a multicultural society. Digital competence is associated with the skills of a specialist in the art industry to use the didactic capabilities of digital technologies in the process of carrying out educational activities, exchange experience, information in the global educational environment, create and distribute digital content, etc.

The use of the ideology of reasonable teaching in the educational process also requires serious self-reflection and self-analysis of innovative pedagogical activity in order to clarify the main shortcomings, barriers in the process of such activities, eliminate them and correct further methods of training organisation. In accordance with this, we consider it expedient to single out reflexive and regulatory competence as a component of the teacher's innovative competence, which is expressed during the implementation in self-control, introspection and self-assessment of the results of the implementation of technological innovations, identifying the reasons for achievements and failures and timely adjusting the methods of innovative activity.

Gaining innovative experience is a rather difficult process, since it requires the implementation of the reflective activity of the acquired experience. Emphasising the special importance of the reflective component in the implementation of innovative learning technologies, it is defined as a "personal achievements regulator". Reflection of personal innovative activity allows to outline the ways of personal development and correction of self-education, stimulates self-knowledge, contributes to the improvement of professional and pedagogical skills and development of an individual style in the conditions of modern education. Reflexive and regulatory component of innovative activity of the teacher realised in the process of understanding the teacher's own professional expertise and experience of colleagues. Only conscious experience is important, because in the process of analytical activity, reflection is carried out, during which the transformation of "raw" experience into personal knowledge occurs.

In the process of reflection and introspection, the teacher gains new knowledge that helps him to manage the strategy of his own self-development, to carry out a creative search, reaching new levels of his professional and pedagogical selfimprovement. This is how the teacher's innovative competence is formed in the changing conditions of a modern "smart" society.

\section{Conclusion}

A modern competitive successful teacher must demonstrate sustainable skills in the use of digital technologies that ensure the interactivity of the learning process, increase the availability of teaching material, contribute to the development of skills for performing complex interdisciplinary tasks, increase students' interest in studying art, and contribute to the development of critical thinking. Consequently, in the context of the development of the modern informationoriented society, digital competence is one of the new requirements for the training and retraining of art critics in the field of modern education. 
Thus, among the main trends in education in the context of global changes, we can name the following: changing the role of the teacher through the digitalisation of learning, individualisation of the educational process through adapted and personalised learning, learning through virtual reality (VR), opening up new opportunities for formal assessment, gamification, creativity and innovation, focus on development of practical skills and abilities of future specialists, and the like. One of the main educational trends of modern higher education is smart education, which is characterised by mobility, flexibility, provides for the generation of new ideas and knowledge, the development of critical thinking, creativity, digital literacy, and the like.

\section{References}

Bedi, K., Hrustek, N. Ž., \& Ćorić, A. (2011, May). Teaching vs. 3D gaming in secondary school. In 2011 Proceedings of the 34th International Convention MIPRO (pp. 1325-1330). IEEE.

Bereczkei, T., \& Csanaky, A. (1996). Mate choice, marital success, and reproduction in a modern society. Ethology and Sociobiology, 17(1), 17-35. https://doi.org/10.1016/0162-3095(95)00104-2

Bezukladnikov, K. E., \& Kruze, B. A. (2015). Modern education technologies for pre-service foreign language teachers. Procedia-Social and Behavioral Sciences, 200, 393-397. https://doi.org/10.1016/j.sbspro.2015.08.084

Burnard, P. (2017). Classroom creativities, pedagogic partnership and the improvisatory space of creative teaching and learning. In Life in Schools and Classrooms (pp. 211-222). Springer, Singapore.

Calderhead, J. (1989). Reflective teaching and teacher education. Teaching and teacher education, 5(1), 43-51. Calderhead, J. (1989). Reflective teaching and teacher education. Teaching and teacher education, 5(1), 43-51. https://doi.org/10.1016/0742-051X(89)90018-8

Cassiday, L. (2011). RESEARCH RENAISSANCE. CHEMICAL \& ENGINEERING NEWS, 89(4), 48-50.

Çil, E., Maccario, N., \& Yanmaz, D. (2016). Design, implementation and evaluation of innovative science teaching strategies for non-formal learning in a natural history museum. Research in Science \& Technological Education, 34(3), 325-341.

Delatte, N. J., Bosela, P. A., \& Bagakas, J. (2013). Implementation and assessment of failure case studies in the engineering curriculum. In Forensic Engineering 2012: Gateway to a Safer Tomorrow (pp. 458-466).

Desai, D., Hamlin, J., \& Mattson, R. (2009). History as Image, Image as History: Contemporary Art and Social Studies Education. Routledge.

Elena, S. (2014). The 'intercultural'teacher-a new response to the teaching career. Procedia-Social and Behavioral Sciences, 128, 111-116. https://doi.org/10.1016/j.sbspro.2014.03.127

Huebner, J. (2005). A possible declining trend for worldwide innovation. Technological Forecasting and Social Change, 72(8), 980-986. https://doi.org/10.1016/j.techfore.2005.01.003

Isabelle, C. (2017). Art at the service of learning French as a Foreign Language Learn French through great artists in the history of art. Synergies France, (11), 191-201. 
Jasonides, K., Karvouniaris, J., \& Zavacopoulou, A. (2016). The Humanities Program: An Innovative Classic. In Revolutionizing K-12 Blended Learning through the $i^{2}$ Flex Classroom Model (pp. 363-399). IGI Global.

Jovanova-Mitkovska, S. (2010). The need of continuous professional teacher development. Procedia-Social and Behavioral Sciences, 2(2), 2921-2926. https://doi.org/10.1016/j.sbspro.2010.03.441

Kravtsova, N. E. (2017). Modernization of modern music and pedagogical education: Prospects and needs. In Modern content of professional development of education managers in terms of global challenges and reforms (pp. 111-128). Mykolaiv: T. V. Yemelyanova.

Kryvylova, O., Sosnickaya, N., Oleksenko, K., Oleksenko, R., \& Khavina, I. (2021). The aqmeological framework for modern higher education as a step towards sustainable development of society. Linguistics and Culture Review, 5(S3), 5564.

Milman, N. B., \& Heinecke, W. F. (2000). Innovative integration of technology in an undergraduate history course. Theory \& Research in Social Education, 28(4), 546-565.

Pakhomova, T. O., Komova, O. S., Belia, V. V., Yivzhenko, Y. V., \& Demidko, E. V. (2021). Transformation of the pedagogical process in higher education during the quarantine. Linguistics and Culture Review, 5(S2), 215-230.

Psacharopoulos, G. (1994). Returns to investment in education: A global update. World development, 22(9), 1325-1343. https://doi.org/10.1016/0305750X(94)90007-8

Realini, C. E., \& Marcos, B. (2014). Active and intelligent packaging systems for a modern society. Meat science, 98(3), 404-419. https://doi.org/10.1016/j.meatsci.2014.06.031

Robertson, C. (2012). Utilising PEARL to teach indigenous art history: A Canadian example. The Australian Journal of Indigenous Education, 41(1), 60-66.

Sacchetti, L., \& Belardo, M. B. (2015). History of healthcare in Argentina and Latin America: an innovative experience in a medical course. InterfaceComunicação, Saúde, Educação, (AHEAD), 00-00.

Schonerl, V., Gorbet, R., Taylor, B., \& Spencer, G. (2007, October). Using crossdisciplinary collaboration to encourage transformative learning. In 2007 37th Annual Frontiers In Education Conference-Global Engineering: Knowledge Without Borders, Opportunities Without Passports (pp. T2H-6). IEEE.

Seligmann, T. (2014). Learning museum: A meeting place for pre-service teachers and museums. Journal of Museum Education, 39(1), 42-53.

Starchikova, I. Y., Shakurova, E. S., \& Moshchenok, G. B. (2018). Design activities as innovative component in liberal arts section of educational process in technical university. Science and Education Perspective, 34(4), 52-57.

Stevens, K. E., Kruck, S. E., Hawkins, J., \& Baker, S. C. (2010). Second Life as a tool for engaging students across the curriculum. In Design and implementation of educational games: Theoretical and practical perspectives (pp. 378-392). IGI Global.

Tiejun, Z. (2017). Creative Merging and Practical Application of" History of Modern Design" Course Online Teaching Platform Construction and Flipped Classroom Teaching Mode. International Journal of Emerging Technologies in Learning, 12(2). 
Ulug, M., Ozden, M. S., \& Eryilmaz, A. (2011). The effects of teachers' attitudes on students' personality and performance. Procedia-Social and Behavioral Sciences, 30, 738-742. https://doi.org/10.1016/j.sbspro.2011.10.144

Vesper, K. H., \& Gartner, W. B. (1997). Measuring progress in entrepreneurship education. Journal of Business venturing, 12(5), 403-421. https:/ / doi.org/10.1016/S0883-9026(97)00009-8

Vityte, B. (2016). Possibilities of the Application of Digital Games in the Implementation of the Curriculum of Arts Subject. Pedagogika, 123(3).

Zhu, T., \& Berry, M. (2018, April). The construction and practice of e-teaching and learning innovative mode for the design history course. In International Conference on E-Learning, E-Education, and Online Training (pp. 320-329). Springer, Cham. 